\title{
Statin Use and Influenza Vaccine Effectiveness in Persons $\geq 65$ Years of Age, Taiwan
}

\author{
Lung-Wen Tsai, ${ }^{1}$ Yung-Tai Chen, ${ }^{1}$ Chia-Jen Shih, Shuo-Ming Ou, Pei-Wen Chao, Shih-Hsiu Lo
}

\begin{abstract}
Medscape ACTIVITY
In support of improving patient care, this activity has been planned and implemented by Medscape, LLC and Emerging Infectious Diseases. Medscape, LLC is jointly accredited by the Accreditation Council for Continuing Medical Education (ACCME), the Accreditation Council for Pharmacy Education (ACPE), and the American Nurses Credentialing Center (ANCC), to provide continuing education for the healthcare team.

Medscape, LLC designates this Journal-based CME activity for a maximum of 1.00 AMA PRA Category 1 Credit(s) ${ }^{\mathrm{TM}}$. Physicians should claim only the credit commensurate with the extent of their participation in the activity.

Successful completion of this CME activity, which includes participation in the evaluation component, enables the participant to earn up to $1.0 \mathrm{MOC}$ points in the American Board of Internal Medicine's (ABIM) Maintenance of Certification (MOC) program. Participants will earn MOC points equivalent to the amount of CME credits claimed for the activity. It is the CME activity provider's responsibility to submit participant completion information to ACCME for the purpose of granting ABIM MOC credit.

All other clinicians completing this activity will be issued a certificate of participation. To participate in this journal CME activity: (1) review the learning objectives and author disclosures; (2) study the education content; (3) take the post-test with a $75 \%$ minimum passing score and complete the evaluation at http://www.medscape.org/journal/eid; and (4) view/print certificate. For CME questions, see page 1353.
\end{abstract}

Release date: May 15, 2020; Expiration date: May 15, 2021

\section{Learning Objectives}

Upon completion of this activity, participants will be able to:

- $\quad$ Evaluate the risks for poor outcomes in elderly patients (aged $>65$ years) who received influenza vaccinations with those in propensity score-matched elderly control individuals who did not receive influenza vaccinations, based on a large-scale, nationwide, Taiwanese population-based cohort study

- Compare vaccine effectiveness between elderly statin users and nonusers, based on a large-scale, nationwide, Taiwanese population-based cohort study

- Assess the clinical implications of comparative risks for poor outcomes in elderly patients who did or did not receive influenza vaccinations and those of comparative vaccine effectiveness between statin users and nonusers, based on a large-scale, nationwide, Taiwanese population-based cohort study

\section{CME Editor}

Amy J. Guinn, BA, MA, Copyeditor, Emerging Infectious Diseases. Disclosure: Amy J. Guinn, BA, MA, has disclosed no relevant financial relationships.

CME Author

Laurie Barclay, MD, freelance writer and reviewer, Medscape, LLC. Disclosure: Laurie Barclay, MD, has disclosed no relevant financial relationships.

\section{Authors}

Disclosures: Lung-Wen Tsai, PhD; Yung-Tai Chen, MD; Chia-Jen Shih, MD; Shuo-Ming Ou, MD; Pei-Wen Chao, MD; and Shih-Hsiu Lo, MD, have disclosed no relevant financial relationships.

Author affiliations: Taipei Medical University Hospital, Taipei, Taiwan (L.-W. Tsai, P.-W. Chao, S.-H. Lo); Taipei City Hospital, Taipei (Y.-T. Chen); University of Taipei, Taipei (Y.-T, Chen); National Yang-Ming University, Taipei (Y.-T. Chen, C.-J. Shih, S.-M. Ou); Taipei Veterans General Hospital, Taipei (S.-M. Ou) 
Debates on whether statin use reduces the effectiveness of influenza vaccines against critical illness and death among persons $\geq 65$ years of age continue. We conducted a study of $9,427,392$ persons $\geq 65$ years of age who did and did not receive influenza vaccinations during 12 consecutive influenza seasons, 2000-01 through 2011-12. Using data from Taiwan's National Health Insurance Research Database, we performed propensity score-matching to compare vaccinated persons with unvaccinated controls. After propensity score-matching, the vaccinated group had lower risks for in-hospital death from influenza and pneumonia and for hospitalization for pneumonia and influenza, circulatory conditions, and critical illnesses compared with the unvaccinated group. We stratified the 2 groups by statin use and analyzed data by interaction analysis and saw no statistically significant difference. We found that influenza vaccine effectively reduced risks for hospitalization and death in persons $\geq 65$ years of age, regardless of statin use.

$\mathrm{E}_{\mathrm{a}}^{\mathrm{p}}$ pidemics of influenza occur nearly every winter and last through spring, causing an average of 226,054 influenza-related hospital admissions and 51,203 influenza-related deaths in the United States annually (1-3). Persons $\geq 65$ years of age are at greater risk for serious complications of influenza and $\approx 90 \%$ of deaths due to influenza and pneumonia occur among this age group $(1,4)$. Taiwan, like other highincome countries, recognizes the importance of influenza vaccination and strongly recommends annual vaccination to prevent complications of influenza and reduce hospitalization rates and death in older persons $(5,6)$.

Persons $\geq 65$ years of age also are at greater risk for coronary atherosclerosis and cardiovascular disease. Statin treatment in this population is crucial, but benefits and risks should guide its use $(7,8)$. In addition to cholesterol-lowering effects that provide cardiovascular benefits, statins have been shown to suppress T-cell activation and exhibit antiinflammatory and immunomodulatory properties (9-12). Few studies have investigated the effect of statins on vaccine effectiveness, but concerns have been raised that statins might interfere with the immune response to influenza vaccines and seem to reduce their effectiveness $(13,14)$. A study of 6,961 trial participants $>65$ years of age from Colombia, Panama, the Philippines, and the United States showed that hemagglutination-inhibiting geometric mean titers to influenza strains were much lower in chronic statin users compared with nonusers (13). Another large-scale retrospective cohort study based on a research database covering influenza seasons for 2002-2011 in the United States revealed reduced influenza vaccine effectiveness against respiratory illness in statin users (14). By contrast, data from another retrospective 5-year cohort study of 1,403,651 statin users matched to nonusers found that use of statins around the time of influenza vaccination does not dramatically affect the risk for influenza-related visits and influenza-related hospitalizations in older adults (15). Another large-scale nationwide population study evaluated whether statin therapy reduced vaccination effectiveness in terms of influenza-associated critical illness hospitalizations and death and suggested high-dose influenza vaccines or vaccines containing adjuvants to boost the immune response might be needed in older populations (16). However, previous studies did not match cases and controls for characteristics, underlying health conditions, or concomitant drug use and did not focus on the outcomes of influenza-related critical illness and death.

We designed a large-scale, nationwide, population-based cohort study to explore heterogeneity of influenza vaccine effectiveness between statin users and nonusers among persons $\geq 65$ years of age in Taiwan. We assessed risks for hospitalization for pneumonia and influenza, circulatory conditions, or critical illness and for in-hospital death and in-hospital death from pneumonia in this age group. We compared the vaccinated group with propensity scorematched control subjects who did not receive influenza vaccinations.

\section{Methods}

\section{Data Source}

We used the data from Taiwan's National Health Insurance Research Database (NHIRD), which has been described in detail elsewhere (17-19). We extracted medical data for persons $\geq 65$ years of age in Taiwan from an NHIRD dataset based on a regulation that prohibits use of the maximal amount of claims data and permits use of data from only one third of older beneficiaries for research purposes. Our dataset included information on all inpatient, emergency department, and outpatient visits; diagnosed illnesses and conditions; prescriptions; and procedures for one third of all persons $\geq 65$ years of age in Taiwan. We used diagnostic and procedural codes from the International Classification of Diseases, 9th Revision, Clinical Modification (ICD-9-CM; https://www.cdc. gov/nchs/icd/icd $9 \mathrm{~cm} . \mathrm{htm}$ ) to ascertain details associated with inpatient and outpatient encounters. Because patient information in the NHIRD is secondary, deidentified, and encrypted, this study was exempted from a full ethics review by the institutional review 
board of Taipei Medical University Hospital (IRB no. 105TMUH-SP-07).

\section{Study Population}

The study period encompassed 12 consecutive influenza seasons from 2000-01 through 2011-12 (14). The study sample was comprised of persons $\geq 65$ years of age who resided in Taiwan during 2000-2012. Persons $\geq 65$ years of age in Taiwan are encouraged to receive influenza vaccines, which are covered by insurance, between October 1 and December 31 each year. For our study, we defined the index date as the date of influenza vaccination for the vaccinated group. To avoid immortal time bias, for the unvaccinated group we randomly assigned index dates that corresponded to those in the vaccinated group. Because the same persons could be part of the unvaccinated group initially and later change to the vaccinated group during the influenza period each year, we did not include the unvaccinated period in our outcome analyses. In each year, we traced participants' NHIRD records from January 1 through September 30 or death.

\section{Statin Exposure}

For each year in the study period, we identified all drug prescriptions written for participants before the index date by using inpatient and ambulatory care order files. For statin users, we identified persons who had initial dispensing date of statin on or before the index date. We defined chronic statin users as those who received and filled a prescription for a statin medication for $\geq 30$ days $(20,21)$.

\section{Outcomes}

The outcomes of interest were in-hospital death and in-hospital death from pneumonia. Our analyses also included severe complications of influenza infections, including hospitalization for pneumonia, circulatory condition, and critical illness. We defined critical illness as hospitalization for acute respiratory failure (ICD-9-CM codes 518.5, 518.81, 518.82, or 96.7) or severe sepsis (ICD-9-CM codes 995.92 or 785.52 ) or organ dysfunction (22).

\section{Statistical Analyses}

We examined the differences of baseline characteristics between the vaccinated group and unvaccinated group by using standardized mean differences. For each participant, we calculated a propensity score for the likelihood of receiving influenza vaccination by using baseline covariates in a multivariate logistic regression model (Appendix Table 1, https://wwwnc.cdc.gov/ EID/article/26/6/19-0646-App1.pdf). For each person in the vaccinated group, we identified 1 person in the unvaccinated group that was frequency-matched according to propensity score (23). We used Cox regression with adjusted imbalance covariates to calculate hazard ratios (HRs) for in-hospital death; inhospital death from pneumonia; and hospitalization for pneumonia, circulatory conditions, and critical illness. We conducted a subgroup analyses and used a likelihood ratio test to explore heterogeneity of vaccine effectiveness between statin users and nonusers. We used SQL Server 2012 (Microsoft, https:/ / www.microsoft.com) for data linkage, processing, and sampling. We performed all analyses by using 2-sided tests in Stata version 12.0 (StataCorp, https:/ / www.stata.com) and considered p $<0.05$ statistically significant.

\section{Results}

Our study included 3,417,212 persons who received influenza vaccination and 6,010,180 who were not vaccinated during 12 consecutive influenza seasons. We matched demographic characteristics and baseline underlying conditions before and after propensity score matching (Table 1). Before propensity score matching, the vaccinated group was older (74.3 years of age) than the unvaccinated group (73.6 years of age) and had higher Charlson Comorbidity Index scores $(7.7 \pm 2.8)$ than the unvaccinated group $(7.2 \pm 2.8)$. The vaccinated group had higher rates of diabetes mellitus (40.3\% vs. $33.3 \%)$ and coronary artery disease $(48.9 \%$ vs. $38.9 \%)$ than the unvaccinated group. In addition, the vaccinated group had higher proportions of use of antiplatelet agents $(16.4 \%)$ than the unvaccinated group $(12.2 \%)$, and more used oral medications for diabetes $(11.7 \%)$ than those in the unvaccinated group $(9.2 \%)$. A total of $167,188(4.9 \%)$ persons in the vaccinated group and $249,822(4.2 \%)$ persons in the unvaccinated group were statin users.

Incidence rates of hospitalization for pneumonia and influenza increased over time. In 2000, the incidence rate was $26.71 / 1,000$ person-years. By 2012, the incidence rate was $41.08 / 1,000$ person-years (Table 2). During 2000-2012, hospitalization for pneumonia and influenza occurred on an average of 23,595 events per year (14,272-33,428 events/year).

Compared with the unvaccinated group, the vaccinated group had lower risks of in-hospital death (adjusted hazard ratio [aHR] 0.69, 95\% CI 0.68-0.69), in-hospital death from pneumonia (aHR 0.72, 95\% CI 0.70-0.73), hospitalization for pneumonia and influenza (aHR 0.84, 95\% CI 0.84-0.85), hospitalization for circulatory conditions (aHR 0.90, 95\% CI 0.90-0.90), and 
hospitalization for critical illnesses (aHR 0.75, 95\% CI 0.74-0.76) (Table 3). For subgroup analyses stratified by statin use, the effects of vaccination on in-hospital death $\left(P_{\text {interaction }}=0.478\right)$, in-hospital death from pneumonia $\left(P_{\text {interaction }}=0.493\right)$, hospitalization for pneumonia and influenza $\left(P_{\text {interaction }}=0.138\right)$, hospitalization for circulatory condition $\left(P_{\text {interaction }}=0.667\right)$, and hospitalization for critical illness $\left(P_{\text {interaction }}=0.375\right)$ were consistent among statin users and nonusers. We also analyzed these data by using the Cox regression model, adjusted for propensity score only, and noted similar results (Appendix Table 2).

\begin{tabular}{|c|c|c|c|c|c|c|}
\hline \multirow[b]{2}{*}{ Characteristics } & \multicolumn{3}{|c|}{ Before propensity score-matching } & \multicolumn{3}{|c|}{ Propensity score-matched } \\
\hline & Vaccinated & Unvaccinated & $\begin{array}{c}\text { Standardized } \\
\text { difference }\end{array}$ & Vaccinated & Unvaccinated & $\begin{array}{c}\text { Standardized } \\
\text { difference }\end{array}$ \\
\hline No. patients & $3,417,212$ & $6,010,180$ & & $3,165,272$ & $3,165,272$ & \\
\hline Mean age, y (SD) & $74.3(6.4)$ & $73.6(6.8)$ & 0.100 & $74.2(6.4)$ & $74.2(6.9)$ & -0.002 \\
\hline \multicolumn{7}{|l|}{ Sex } \\
\hline M & $1,707,483(50.0)$ & $2,908,606(48.4)$ & 0.031 & $1,559,852(49.3)$ & $1,550,848(49.0)$ & 0.006 \\
\hline $\mathrm{F}$ & $1,709,729(50.0)$ & $3,101,574(51.6)$ & & $1,605,420(50.7)$ & $1,614,424(51.0)$ & \\
\hline \multicolumn{7}{|c|}{ Monthly income, \$ Taiwan } \\
\hline Dependent $†$ & $1,234,769(36.1)$ & $2,527,696(42.1)$ & -0.122 & $1,190,930(37.6)$ & $1,197,102(37.8)$ & -0.004 \\
\hline$<19,100$ & $794,513(23.3)$ & $1,365,600(22.7)$ & 0.013 & $728,908(23.0)$ & $721,281(22.8)$ & 0.006 \\
\hline $19,100-41,999$ & $1,367,022(40.0)$ & $2,054,058(34.2)$ & 0.121 & $1,224,632(38.7)$ & $1,226,438(38.7)$ & -0.001 \\
\hline$\geq 42,000$ & $20,908(0.6)$ & $62,826(1.0)$ & -0.048 & $20,802(0.7)$ & $20,451(0.6)$ & 0.001 \\
\hline \multicolumn{7}{|l|}{ Urbanization $\ddagger$} \\
\hline Level 1 & $988,136(28.9)$ & $1,833,258(30.5)$ & -0.035 & $926,242(29.3)$ & $925,049(29.2)$ & 0.001 \\
\hline Level 2 & $2,194,465(64.2)$ & $3,793,218(63.1)$ & 0.023 & $2,025,556(64.0)$ & $2,025,109(64.0)$ & 0.000 \\
\hline Level 3 & $199,301(5.8)$ & $320,751(5.3)$ & 0.022 & $180,635(5.7)$ & $181,562(5.7)$ & -0.001 \\
\hline Level 4 & $35,310(1.0)$ & $62,953(1.0)$ & -0.001 & $32,839(1.0)$ & $33,552(1.1)$ & -0.002 \\
\hline \multicolumn{7}{|c|}{ No. outpatient visits in the previous $12 \mathrm{mo}$} \\
\hline $0-10$ & $504,028(14.7)$ & $1,831,616(30.5)$ & -0.383 & $504,014(15.9)$ & $500,316(15.8)$ & 0.003 \\
\hline $11-20$ & $869,805(25.5)$ & $1,598,542(26.6)$ & -0.026 & $851,438(26.9)$ & $854,335(27.0)$ & -0.002 \\
\hline $21-30$ & $776,389(22.7)$ & $1,106,821(18.4)$ & 0.107 & $719,783(22.7)$ & $721,771(22.8)$ & -0.001 \\
\hline $31-40$ & $522,170(15.3)$ & $651,142(10.8)$ & 0.132 & 462,035 (14.6) & $462,408(14.6)$ & 0.000 \\
\hline$>40$ & $744,820(21.8)$ & 822,059 (13.7) & 0.214 & $628,002(19.8)$ & $626,442(19.8)$ & 0.001 \\
\hline CCl score (SD)§ & $7.7(2.8)$ & $7.2(2.8)$ & 0.236 & $7.8(2.8)$ & $7.8(2.9)$ & -0.006 \\
\hline \multicolumn{7}{|l|}{ Underlying conditions } \\
\hline $\begin{array}{l}\text { Cerebrovascular } \\
\text { disease }\end{array}$ & $1,151,954(33.7)$ & $1,703,465(28.3)$ & 0.116 & $1,047,165(33.1)$ & $1,052,107$ (33.2) & -0.003 \\
\hline Diabetes & $1,377,596(40.3)$ & $2,000,525(33.3)$ & 0.146 & $1,246,943(39.4)$ & $1,252,696(39.6)$ & -0.004 \\
\hline Hypertension & $2,568,836(75.2)$ & $3,931,874(65.4)$ & 0.215 & $2,344,103(74.1)$ & $2,351,157$ (74.3) & -0.005 \\
\hline CAD & $1,672,350(48.9)$ & $2,340,127(38.9)$ & 0.203 & $1,520,516(48.0)$ & $1,447,015(45.7)$ & 0.047 \\
\hline Myocardial infarction & $158,688(4.6)$ & $228,094(3.8)$ & 0.042 & $143,777(4.5)$ & $144,573(4.6)$ & -0.001 \\
\hline PVD & $238,514(7.0)$ & $324,691(5.4)$ & 0.065 & $217,314(6.9)$ & $210,393(6.6)$ & 0.009 \\
\hline Heart failure & 555,349 (16.3) & $792,171(13.2)$ & 0.087 & $503,135(15.9)$ & $506,674(16.0)$ & -0.003 \\
\hline Dyslipidemia & $1,557,151(45.6)$ & $2,231,936(37.1)$ & 0.172 & $1,436,998(45.4)$ & $1,340,441(42.3)$ & 0.062 \\
\hline Chronic liver disease & $1,067,001(31.2)$ & $1,460,809$ (24.3) & 0.155 & $950,911(30.0)$ & $951,575(30.1)$ & 0.000 \\
\hline CKD & $664,324(19.4)$ & $917,408(15.3)$ & 0.110 & $596,302(18.8)$ & 597,911 (18.9) & -0.001 \\
\hline Peptic ulcer disease & $1,904,442(55.7)$ & $2,764,223(46.0)$ & 0.196 & $1,720,590(54.4)$ & $1,723,618(54.5)$ & -0.002 \\
\hline Dementia & $249,766(7.3)$ & $370,758(6.2)$ & 0.045 & $228,856(7.2)$ & $231,226(7.3)$ & -0.003 \\
\hline Valvular heart disease & $424,657(12.4)$ & $596,580(9.9)$ & 0.079 & $383,055(12.1)$ & $384,592(12.2)$ & -0.001 \\
\hline Drug abuse & $48,591(1.4)$ & $74,326(1.2)$ & 0.016 & $45,499(1.4)$ & $45,816(1.4)$ & -0.001 \\
\hline Atrial fibrillation & $160,148(4.7)$ & 235,626 (3.9) & 0.038 & $146,674(4.6)$ & $147,989(4.7)$ & -0.002 \\
\hline \multicolumn{7}{|l|}{ Medications } \\
\hline Antiplatelet agents & $559,272(16.4)$ & $735,104(12.2)$ & 0.118 & $491,897(15.5)$ & $493,185(15.6)$ & -0.001 \\
\hline Insulin & $42,022(1.2)$ & $58,973(1.0)$ & 0.024 & $38,581(1.2)$ & $38,823(1.2)$ & -0.001 \\
\hline Oral diabetic drugs & $399,409(11.7)$ & $552,935(9.2)$ & 0.081 & $358,531(11.3)$ & $361,189(11.4)$ & -0.003 \\
\hline Diuretics & $301,500(8.8)$ & $420,868(7.0)$ & 0.067 & $270,816(8.6)$ & $272,637(8.6)$ & -0.002 \\
\hline $\begin{array}{l}\text { Calcium channel } \\
\text { blockers }\end{array}$ & 651,895 (19.1) & $892,880(14.9)$ & 0.113 & $580,984(18.4)$ & $583,106(18.4)$ & -0.002 \\
\hline Beta-blockers & $413,542(12.1)$ & $583,937(9.7)$ & 0.077 & $371,599(11.7)$ & $372,374(11.8)$ & -0.001 \\
\hline ACEI/ARB & 508,701 (14.9) & $719,943(12.0)$ & 0.085 & $459,520(14.5)$ & $461,934(14.6)$ & -0.002 \\
\hline Statins & $167,188(4.9)$ & $249,822(4.2)$ & 0.035 & $155,133(4.9)$ & $155,624(4.9)$ & -0.001 \\
\hline Propensity score & $0.42(0.13)$ & $0.33(0.14)$ & 0.662 & $0.406(0.129)$ & $0.406(0.129)$ & 0.000 \\
\hline \multicolumn{7}{|c|}{$\begin{array}{l}\text { "Values are no. (\%) except as indicated. ACEI, angiotensin-converting enzyme inhibitor; ARB, angiotensin II receptor blocker; CAD, coronary artery } \\
\text { disease; CCI, Charlson Comorbidity Index; CKD, chronic kidney disease; PVD, peripheral vascular disease. } \\
\text { tDependent persons are those without an income. } \\
\text { fUrbanization levels in Taiwan are divided into } 4 \text { strata according to the Taiwan National Health Research Institute publications. Level } 1 \text { designates the } \\
\text { most urbanized areas, and level } 4 \text { designates the least urbanized areas. } \\
\S \mathrm{CCl} \text { score is used to determine overall systemic health. Increased CCI scores are indicative of stepwise increases in the cumulative mortality. }\end{array}$} \\
\hline
\end{tabular}


Table 2. Incidence of hospitalization for pneumonia and influenza in persons $\geq 65$ years of age during 2000-2012, Taiwan

\begin{tabular}{cccc}
\hline Year & No. events & Person-years & $\begin{array}{c}\text { Incidence/ } 1,000 \\
\text { person-years }\end{array}$ \\
\hline 2000 & 14,272 & 534,348 & 26.71 \\
2001 & 17,342 & 596,594 & 29.07 \\
2002 & 17,383 & 615,868 & 28.23 \\
2003 & 19,298 & 610,215 & 31.62 \\
2004 & 21,807 & 640,872 & 34.03 \\
2005 & 19,909 & 662,198 & 30.07 \\
2006 & 22,394 & 664,194 & 33.72 \\
2007 & 24,148 & 699,617 & 34.52 \\
2008 & 25,829 & 713,500 & 36.20 \\
2009 & 28,226 & 730,645 & 38.63 \\
2010 & 31,945 & 733,967 & 43.52 \\
2011 & 33,428 & 746,025 & 44.81 \\
2012 & 30,760 & 748,838 & 41.08 \\
\hline
\end{tabular}

\section{Discussion}

In this nationwide population-based study in Taiwan, we investigated the effects of statin therapy on the risks for in-hospital death and severe complications of influenza infections in 9,427,392 persons $\geq 65$ years of age during influenza seasons from 2000-01 through 2011-12. We found that vaccinated groups had lower risks than unvaccinated groups for in-hospital death; in-hospital death from pneumonia; and hospitalization for pneumonia and influenza, circulatory conditions, and critical illness. In the subgroup analysis stratified by statin use, the observed outcome differences across stain users and nonusers were consistent with chance.

Statins might exert antiinflammatory effects by inhibiting the major histocompatibility complex class II pathway of antigen presentation (24), preventing accumulation and recruitment of monocytes (25), reducing cytokine production by immune cells $(26,27)$, and impairing the activation of T cells $(9,28)$. Previous studies that directly address statin use and vaccine effectiveness have had conflicting results. A randomized clinical study of 150 healthy persons failed to find any difference in antibody responses to hepatitis A vaccine among those receiving atorvastatin and those receiving a placebo (29); that study was limited because only statin therapy initiated on the day of randomization, not prior chronic statin therapy, was considered. In contrast, another study of 105,874 vaccinated persons $(39,342$ statin users and 66,532 nonusers) and 141,714 unvaccinated persons (52,685 statin users and 89,029 nonusers) revealed reduced influenza vaccine effectiveness against acute respiratory illness among statin users compared with nonusers during influenza seasons (14). However, that study was limited by healthy-user bias $(30,31)$ and did not match characteristics in controls.

Other large-scale studies have revealed suboptimal influenza vaccine effectiveness in persons $\geq 65$ years of age because of age-related decline in the immune response, multiple underlying conditions, and concomitant medication use with possible secondary interactions $(32,33)$. To address the potential negative effects of concomitant statin therapy on vaccine effectiveness, a prior post hoc analysis showed that influenza antibody titers were much lower in those receiving chronic statin therapy compared with those not receiving statin therapy (13). However, the association between antibody titers and adverse clinical outcomes was not characterized further, raising concern about the actual clinical implications. Another populationbased retrospective cohort study of 1,403,651 Medicare beneficiaries $\geq 65$ years of age in the United States matched statin users to nonusers and found that statin use does not dramatically affect the risk for influenzarelated visits and influenza-related hospitalizations in this population (15). However, the study did not determine whether chronic statin use had any implication for major adverse cardiovascular events or death.

We found that, among persons $\geq 65$ years of age, vaccinated statin users and nonusers had lower risks of in-hospital death and severe complications of influenza infections compared with unvaccinated groups. In further analyses, we found no statistically significant difference and interaction between statin use and hospitalization for pneumonia, influenza, or circulatory conditions. However, vaccine effectiveness against critical illness slightly increased in statin users compared with nonusers, suggesting that the context of benefits of statins for cardiovascular outcomes could play a role for critically ill patients (34).

The strengths of our study include the use of a large nationwide population-based dataset, encompassing data from $9,427,392$ patients $\geq 65$ years of age. Our study covered 12 influenza seasons, from 200001 through 2011-12, aiding comparison of the effects of statins on the risks for death and hospital admission for major pulmonary and circulatory events in older vaccinated and unvaccinated persons.

Our study has some limitations. First, relevant details enabling characterization of the geographic spread of influenza activity as sporadic, local, regional, or widespread, and information on influenza virus subtypes were not available in the NHIRD dataset. Therefore, we could not identify the effects of statin therapy on the spread of influenza. Second, we used data on persons registered in the national health insurance program, which included information on adverse clinical outcomes caused by local and widespread influenza, but we cannot rule out the possibility of diagnostic misclassification. Third, with a such large sample in our study, a statistical test would 
Table 3. Comparison of statin users and nonusers $\geq 65$ years of age for incidence and risk for hospitalization, pneumonia, circulatory conditions, critical illness, and death who are vaccinated and unvaccinated for influenza, Taiwan*

\begin{tabular}{|c|c|c|c|c|c|c|c|c|}
\hline \multirow[b]{2}{*}{ Characteristics } & \multicolumn{3}{|c|}{ Vaccinated } & \multicolumn{3}{|c|}{ Unvaccinated (referent) } & \multicolumn{2}{|c|}{ Hazard ratio $(95 \% \mathrm{Cl}) \dagger$} \\
\hline & No. & Person-years & Incidence & No. & Person-years & Incidence & Crude & Adjusted \\
\hline In-hospital death§ & 38,320 & $2,984,344$ & 12.84 & 55,405 & $2,949,054$ & 18.79 & $\begin{array}{c}0.68 \\
(0.67-0.69)\end{array}$ & $\begin{array}{c}0.69 \\
(0.68-0.69)\end{array}$ \\
\hline Statin user & 1,478 & 147,164 & 10.04 & 22,097 & 146,668 & 14.30 & $\begin{array}{c}0.70 \\
(0.66-0.75)\end{array}$ & $\begin{array}{c}0.71 \\
(0.67-0.76)\end{array}$ \\
\hline Statin nonuser & 36,842 & $2,837,180$ & 12.99 & 53,308 & $2,802,386$ & 19.02 & $\begin{array}{c}0.68 \\
(0.67-0.69)\end{array}$ & $\begin{array}{c}0.68 \mid \\
(0.68-0.69)\end{array}$ \\
\hline $\begin{array}{l}\text { In-hospital death } \\
\text { from pneumoniaף }\end{array}$ & 15,057 & $2,984,931$ & 5.04 & 20,699 & $2,950,157$ & 7.02 & $\begin{array}{c}0.72 \\
(0.70-0.73)\end{array}$ & $\begin{array}{c}0.72 \\
(0.70-0.73)\end{array}$ \\
\hline Statin user & 503 & 147,202 & 3.42 & 665 & 146,723 & 4.53 & $\begin{array}{c}0.75 \\
(0.67-0.85)\end{array}$ & $\begin{array}{c}0.75 \\
(0.67-0.85)\end{array}$ \\
\hline Statin nonuser & 14,554 & $2,837,730$ & 5.13 & 20,034 & $2,803,435$ & 7.15 & $\begin{array}{c}0.72 \\
(0.70-0.73)\end{array}$ & $\begin{array}{c}0.72 \\
(0.70-0.73)\end{array}$ \\
\hline $\begin{array}{l}\text { Hospitalization for } \\
\text { pneumonia or } \\
\text { influenza\# }\end{array}$ & 103,395 & $2,946,802$ & 35.09 & 121,776 & $2,907,115$ & 41.89 & $\begin{array}{c}0.84 \\
(0.83-0.84)\end{array}$ & $\begin{array}{c}0.84 \\
(0.84-0.85)\end{array}$ \\
\hline Statin user & 3,967 & 145,687 & 27.23 & 4,810 & 144,805 & 33.22 & $\begin{array}{c}0.82 \\
(0.79-0.86)\end{array}$ & $\begin{array}{c}0.82 \\
(0.79-0.86)\end{array}$ \\
\hline Statin nonuser & 99,428 & $2,801,115$ & 35.50 & 116,966 & $2,762,309$ & 42.34 & $\begin{array}{c}0.84 \\
(0.83-0.85)\end{array}$ & $\begin{array}{c}0.84 \\
(0.84-0.85)\end{array}$ \\
\hline $\begin{array}{l}\text { Hospitalization for } \\
\text { circulatory } \\
\text { condition }^{\star *}\end{array}$ & 394,245 & $2,801,412$ & 140.73 & 430,954 & $2,750,954$ & 156.66 & $\begin{array}{c}0.90 \\
(0.90-0.90)\end{array}$ & $\begin{array}{c}0.90 \\
(0.90-0.90)\end{array}$ \\
\hline Statin user & 25,141 & 134,914 & 186.35 & 27,991 & 132,843 & 210.71 & $\begin{array}{c}0.89 \\
(0.87-0.90)\end{array}$ & $\begin{array}{c}0.90 \\
(0.88-0.91)\end{array}$ \\
\hline Statin nonuser & 369,104 & $2,666,498$ & 138.42 & 402,963 & $2,618,111$ & 153.91 & $\begin{array}{c}0.90 \\
(0.90-0.90)\end{array}$ & $\begin{array}{c}0.90 \\
(0.89-0.90)\end{array}$ \\
\hline $\begin{array}{l}\text { Hospitalization for } \\
\text { critical illness } \dagger \dagger\end{array}$ & 62,018 & $2,968,927$ & 20.89 & 82,602 & $2,929,804$ & 28.19 & $\begin{array}{c}0.74 \\
(0.73-0.75)\end{array}$ & $\begin{array}{c}0.75 \\
(0.74-0.76)\end{array}$ \\
\hline Statin user & 2,614 & 146,432 & 17.85 & 3,574 & 145,677 & 24.53 & $\begin{array}{c}0.73 \\
(0.69-0.77)\end{array}$ & $\begin{array}{c}0.74 \\
(0.71-0.78)\end{array}$ \\
\hline Statin nonuser & 59,404 & $2,822,496$ & 21.05 & 79,028 & $2,784,127$ & 28.39 & $\begin{array}{c}0.74 \\
(0.73-0.75)\end{array}$ & $\begin{array}{c}0.75 \\
(0.74-0.76)\end{array}$ \\
\hline $\begin{array}{l}\text { *Values after propensi } \\
\dagger \text { Calculated by Cox re } \\
\text { †Per } 1,000 \text { person-yea } \\
\text { SInteraction } p=0.478 . \\
\text { TIInteraction } p=0.493 \\
\text { \#Interaction } p=0.138 \text {. } \\
{ }^{*} \text { Interaction } p=0.667 \\
\text { t†Interaction } p=0.375\end{array}$ & . & , elve & 政 & 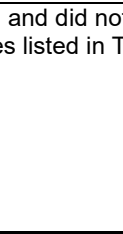 & cive in & $\begin{array}{l}\text { accinatio } \\
p<0.001\end{array}$ & & \\
\hline
\end{tabular}

easily demonstrate a significant difference. However, the risk difference in the vaccinated group compared with the unvaccinated group ranged from $10 \%$ to $31 \%$, and the difference is not small. For subgroup analyses, the overall treatment effects also are consistent across subsets of patients. In addition, although we explored the interaction between statin use and the effectiveness of the influenza vaccine, whether other drugs exerting similar pleiotropic effects, such as aspirin and nonsteroidal antiinflammatory drugs, or other vaccines commonly used in this population, including pneumococcal and herpes vaccines, have similar interactions is unknown. Finally, our study included only persons $\geq 65$ years of age, and our results cannot be extrapolated to younger persons who often elicit stronger immune responses after vaccination.

In conclusion, influenza vaccination was associated with lower risks of in-hospital death and hospitaliza- tion for pulmonary and circulatory adverse outcomes in persons $\geq 65$ years of age in Taiwan. Of note, the rate of hospitalization for critical illness was slightly lower in statin users than that for nonusers. These findings indicate that influenza vaccination should continue to be encouraged in older populations because it reduces disease-specific hospitalization and death. In addition, statin use might enhance the protective effects of the vaccine against critical illness.

This study was based on data from the National Health Insurance Research Database provided by Bureau of National Health Insurance (BNHI) of the Department of Health and managed by the National Health Research Institute. The conclusions presented in this study are those of the authors and do not necessarily reflect the views of the BNHI, the Department of Health, or the National Health Research Institute. 
This work was supported in part by the Novel Bioengineering and Technological Approaches to Solve Two Major Health Problems in Taiwan sponsored by the Taiwan Ministry of Science and Technology (MOST) Academic Excellence Program (MOST grant nos. 105-2633B-009-003, 107-2314-B-075-052, and 108-2314-B-075-008); Wan Fang Hospital (grant nos. 105swf0 and, 106-swf-06); Taipei City Government (grant nos. 10701-62-054 and10801-62-051); Taipei Veterans General Hospital (grant nos. V105A-003, V106B-009, V107B-027, V108B-023, V109B-022, and V109D50-001-MY3-1); Taipei Veterans General Hospital-National Yang-Ming University Excellent Physician Scientists Cultivation Program (grant no. 104-V-B-044); Taipei Medical University Hospital (grant no. 105TMUH-SP-07).

\section{About the Author}

Dr. Tsai is a professor of infectious diseases at Tapai University. His research interests include epidemiology and public health.

\section{References}

1. Thompson WW, Shay DK, Weintraub E, Brammer L, Cox N, Anderson LJ, et al. Mortality associated with influenza and respiratory syncytial virus in the United States. JAMA. 2003;289:179-86. https://doi.org/10.1001/ jama.289.2.179

2. Thompson WW, Shay DK, Weintraub E, Brammer L, Bridges CB, Cox NJ, et al. Influenza-associated hospitalizations in the United States. JAMA. 2004;292:133340. https://doi.org/10.1001/jama.292.11.1333

3. Chandrasekhar R, Sloan C, Mitchel E, Ndi D, Alden N, Thomas A, et al. Social determinants of influenza hospitalization in the United States. Influenza Other Respir Viruses. 2017;11:479-88. https://doi.org/10.1111/irv.12483

4. Sprenger MJ, Van Naelten MA, Mulder PG, Masurel N. Influenza mortality and excess deaths in the elderly, 1967-82. Epidemiol Infect. 1989;103:633-41. https:/ / doi.org/10.1017/ S0950268800031034

5. Nichol KL, Nordin JD, Nelson DB, Mullooly JP, Hak E. Effectiveness of influenza vaccine in the communitydwelling elderly. N Engl J Med. 2007;357:1373-81. https://doi.org/10.1056/NEJMoa070844

6. Wang CS, Wang ST, Lai CT, Lin LJ, Lee CT, Chou P. Reducing major cause-specific hospitalization rates and shortening hospital stays after influenza vaccination. Clin Infect Dis. 2004;39:1604-10. https://doi.org/10.1086/425323

7. Savarese G, Gotto AM Jr, Paolillo S, D'Amore C, Losco T, Musella F, et al. Benefits of statins in elderly subjects without established cardiovascular disease: a meta-analysis. J Am Coll Cardiol. 2013;62:2090-9. https:// doi.org/10.1016/ j.jacc.2013.07.069

8. Teng M, Lin L, Zhao YJ, Khoo AL, Davis BR, Yong QW, et al. Statins for primary prevention of cardiovascular disease in elderly patients: systematic review and meta-analysis. Drugs Aging. 2015;32:649-61. https:/ / doi.org/10.1007/ s40266-015-0290-9

9. Fehr T, Kahlert C, Fierz W, Joller-Jemelka HI, Riesen WF, Rickli $\mathrm{H}$, et al. Statin-induced immunomodulatory effects on human T cells in vivo. Atherosclerosis. 2004;175:83-90. https:/ / doi.org/10.1016/j.atherosclerosis.2004.02.016

10. Blanco-Colio LM, Tuñón J, Martín-Ventura JL, Egido J. Anti-inflammatory and immunomodulatory effects of statins. Kidney Int. 2003;63:12-23. https:/ / doi.org/10.1046/ j.1523-1755.2003.00744.x

11. Jain MK, Ridker PM. Anti-inflammatory effects of statins: clinical evidence and basic mechanisms. Nat Rev Drug Discov. 2005;4:977-87. https:// doi.org/10.1038/nrd1901

12. Chow SC. Immunomodulation by statins: mechanisms and potential impact on autoimmune diseases. Arch Immunol Ther Exp (Warsz). 2009;57:243-51. https:/ / doi.org/10.1007/ s00005-009-0038-5

13. Black S, Nicolay U, Del Giudice G, Rappuoli R. Influence of statins on influenza vaccine response in elderly individuals. J Infect Dis. 2016;213:1224-8. https:/ / doi.org/10.1093/ infdis/jiv456

14. Omer SB, Phadke VK, Bednarczyk RA, Chamberlain AT, Brosseau JL, Orenstein WA. Impact of statins on influenza vaccine effectiveness against medically attended acute respiratory illness. J Infect Dis. 2016;213:1216-23. https://doi.org/10.1093/infdis/jiv457

15. Izurieta HS, Chillarige Y, Kelman JA, Forshee R, Qiang Y, Wernecke $M$, et al. Statin use and risks of influenza-related outcomes among older adults receiving standard-dose or high-dose influenza vaccines through Medicare during 2010-2015. Clin Infect Dis. 2018;67:378-87. https://doi.org/ $10.1093 /$ cid/ciy100

16. Ortiz JR, Neuzil KM, Shay DK, Rue TC, Neradilek MB, Zhou H, et al. The burden of influenza-associated critical illness hospitalizations. Crit Care Med. 2014;42:2325-32. https://doi.org/10.1097/CCM.0000000000000545

17. Shih CJ, Ou SM, Chao PW, Kuo SC, Lee YJ, Yang CY, et al. Risks of death and stroke in patients undergoing hemodialysis with new-onset atrial fibrillation: a competing-risk analysis of a nationwide cohort. Circulation. 2016;133:265-72. https:/ / doi.org/10.1161/ CIRCULATIONAHA.115.018294

18. Ou SM, Shih CJ, Chao PW, Chu H, Kuo SC, Lee YJ, et al. Effects on clinical outcomes of adding dipeptidyl peptidase-4 inhibitors versus sulfonylureas to metformin therapy in patients with type 2 diabetes mellitus. Ann Intern Med. 2015;163:663-72. https://doi.org/10.7326/ M15-0308

19. Shih CJ, Chu H, Chao PW, Lee YJ, Kuo SC, Li SY, et al. Long-term clinical outcome of major adverse cardiac events in survivors of infective endocarditis: a nationwide population-based study. Circulation. 2014;130:1684-91. https:// doi.org/10.1161/CIRCULATIONAHA.114.012717

20. Lee CC, Lee MG, Hsu TC, Porta L, Chang SS, Yo CH, et al. A population-based cohort study on the drug-specific effect of statins on sepsis outcome. Chest. 2018;153:805-15. https://doi.org/10.1016/j.chest.2017.09.024

21. Chanin JM, Yang DC, Haider MA, Swaminathan RV, Kim LK, Charitakis K, et al. Impact of chronic statin therapy on postprocedural contrast-induced nephropathy in patients undergoing non-emergent percutaneous coronary intervention. J Invasive Cardiol. 2015;27:490-6.

22. Ortiz JR, Neuzil KM, Cooke CR, Neradilek MB, Goss CH, Shay DK. Influenza pneumonia surveillance among hospitalized adults may underestimate the burden of severe influenza disease. PLoS One. 2014;9:e113903. https:/ / doi.org/10.1371/journal.pone.0113903

23. Stürmer T, Joshi M, Glynn RJ, Avorn J, Rothman KJ, Schneeweiss S. A review of the application of propensity score methods yielded increasing use, advantages in specific 
settings, but not substantially different estimates compared with conventional multivariable methods. J Clin Epidemiol. 2006;59:437-47. https:/ / doi.org/10.1016/ j.jclinepi.2005.07.004

24. Ghittoni R, Napolitani G, Benati D, Ulivieri C, Patrussi L, Laghi Pasini F, et al. Simvastatin inhibits the MHC class II pathway of antigen presentation by impairing Ras superfamily GTPases. Eur J Immunol. 2006;36:2885-93. https:/ / doi.org/10.1002/ eji.200636567

25. Han KH, Ryu J, Hong KH, Ko J, Pak YK, Kim JB, et al. HMG-CoA reductase inhibition reduces monocyte CC chemokine receptor 2 expression and monocyte chemoattractant protein-1-mediated monocyte recruitment in vivo. Circulation. 2005;111:1439-47. https:// doi.org/ 10.1161/01.CIR.0000158484.18024.1F

26. Azor MH, dos Santos JC, Futata EA, de Brito CA, Maruta CW, Rivitti EA, et al. Statin effects on regulatory and proinflammatory factors in chronic idiopathic urticaria. Clin Exp Immunol. 2011;166:291-8. https:/ / doi.org/10.1111/ j.1365-2249.2011.04473.x

27. Zhang J, Osawa S, Takayanagi Y, Ikuma M, Yamada T, Sugimoto M, et al. Statins directly suppress cytokine production in murine intraepithelial lymphocytes. Cytokine. 2013;61:540-5. https://doi.org/10.1016/ j.cyto.2012.12.006

28. Ghittoni R, Patrussi L, Pirozzi K, Pellegrini M, Lazzerini PE, Capecchi PL, et al. Simvastatin inhibits T-cell activation by selectively impairing the function of Ras superfamily GTPases. FASEB J. 2005;19:605-7. https://doi.org/10.1096/ fj.04-2702fje

29. Packard RR, Schlegel S, Senouf D, Burger F, Sigaud P, Perneger T, et al. Atorvastatin treatment and vaccination efficacy. J Clin Pharmacol. 2007;47:1022-7. https:/ / doi.org/ 10.1177/0091270007302169

30. Brookhart MA, Patrick AR, Dormuth C, Avorn J, Shrank W, Cadarette SM, et al. Adherence to lipid-lowering therapy and the use of preventive health services: an investigation of the healthy user effect. Am J Epidemiol. 2007;166:348-54. https://doi.org/10.1093/aje/kwm070

31. Shrank WH, Patrick AR, Brookhart MA. Healthy user and related biases in observational studies of preventive interventions: a primer for physicians. J Gen Intern Med. 2011;26:546-50. https://doi.org/10.1007/ s11606-010-1609-1

32. Goodwin K, Viboud C, Simonsen L. Antibody response to influenza vaccination in the elderly: a quantitative review. Vaccine. 2006;24:1159-69. https://doi.org/10.1016/ j.vaccine.2005.08.105

33. Mannino S, Villa M, Apolone G, Weiss NS, Groth N, Aquino I, et al. Effectiveness of adjuvanted influenza vaccination in elderly subjects in northern Italy. Am J Epidemiol. 2012;176:527-33. https:/ / doi.org/10.1093/ aje/kws313

34. Westin GG, Armstrong EJ, Bang H, Yeo KK, Anderson D, Dawson DL, et al. Association between statin medications and mortality, major adverse cardiovascular event, and amputation-free survival in patients with critical limb ischemia. J Am Coll Cardiol. 2014;63:682-90. https:// doi.org/10.1016/j.jacc.2013.09.073

Addresses for correspondence: Shih-Hsiu Lo, Department of Urology, Taipei Medical University Hospital, Taipei, Taiwan; email: 153031@h.tmu.edu.tw; Shuo-Ming Ou, Department of Nephrology, Taipei Veterans General Hospital, Taipei, 11217, Taiwan; email: okokyytt@gmail.com

\section{EID Podcast: Visions of Matchstick Men and Icons of Industrialization}

Byron Breedlove, managing editor of the journal, discusses and reads his November 2017 cover art essay. This cover (Going to Work, 1943) is by English artist Laurence Stephen Lowry (1887-1976) who died of pneumonia in 1976.

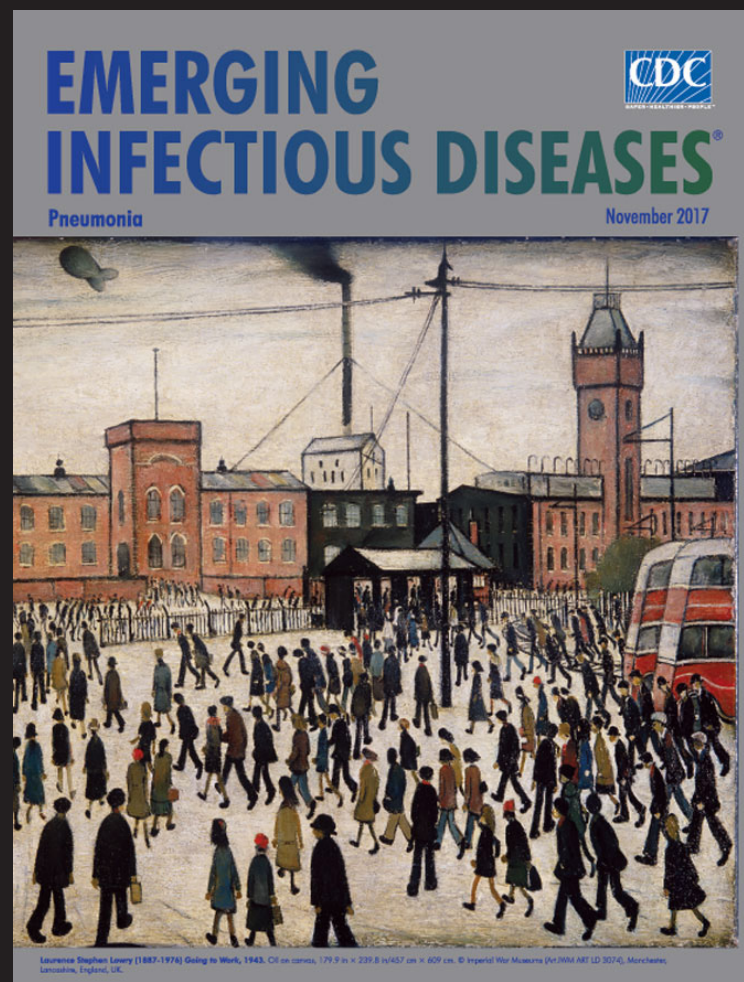

Visit our website to listen: https://www2c.cdc.gov/ podcasts/player.asp?f $=\mathbf{8 6 4 7 1 7 3}$ EMEREINC INFECTIOUS DISEASES 